\title{
Modeling Real Private Consumption Expenditure in Bulgaria after the Currency Board Implementation (1997-2005)
}

\author{
Aleksandar Vasilev*
}

\begin{abstract}
In this paper, an econometric model of consumption in Bulgaria for the period 1997-2005 is constructed. The Error-Correction Model (ECM) approach is employed and long-run relationship between household consumption and income was found. The primary purpose of this empirical paper is to get a better understanding of the factors driving household consumption in Bulgaria and to estimate a consumption function to be used for medium-term forecasting. It is shown that all households behave in a Keynesian way, basing their consumption decisions on current income.
\end{abstract}

Keywords: Keynesian consumption function, Permanent Income Hypothesis, Error Correction Model

JEL Classification: E21; E27

\section{Introduction and Motivation}

This paper models consumption behavior of households in Bulgaria after the financial crisis in 1996-7. The hyperinflation, and the currency board implemented later in 1997 were structural breaks for the economy. Consumer behavior changed dramatically - most of the people lost the savings they kept for a "rainy day" and found their real incomes reduced. Households had to form new consumption paths, consistent with the new economic environment. Thus any study that uses data before the financial crisis is subject to the Lucas' critique (Lucas 1976): all parameters of the consumption function, estimated with pre-97 data will be conditional on the economic conjecture at that time and will give bad forecasts. Luckily, there are enough quarterly observations for the period after the currency board was implemented for an sensible study (in econometric sense) to be pursued.

\footnotetext{
* Aleksandar Vasilev is at American University in Bulgaria, Bulgaria.
} 
Private consumption expenditure is the largest component of the Gross Domestic product (GDP) in Bulgaria. That makes it an extremely important component of the aggregate demand, not only because it influences economic growth, but also for business cycle considerations. In this respect, the study of consumption is relevant.

In this paper, an econometric model of consumption in Bulgaria for the period 1997-2005 will be constructed. The Error-Correction Model (ECM) approach will be employed and time-series data will be used in the regression. The primary purpose of this empirical paper will be to get a better understanding of the factors driving household consumption in Bulgaria and to estimate a consumption function to be used for medium-term forecasting.

Consumption will be expressed as a function of explanatory variables such as income, wealth and others that will capture income uncertainty and inter-temporal substitution effects. This kind of studies are common in developed countries, but are a rare event in small countries such as Bulgaria, due to short time series especially for the period after the financial and banking crisis of 1996-97. The studies using household-level data for Bulgaria are by Petrova et al. (1996) and Skoufias (2004). However, both use survey data from 1992-95 and 1994, respectively, which is before the period of interest. A more modern treatments, though with a different focus, can be found in Chukalev (2010) and Genchev (2012).

The paper is organized as follows: Section 2 presents the literature review. Sections 3 describes the data used, the econometric methodology applied and discusses the results obtained from the estimation. Section 4 summarizes the contribution and concludes.

\section{Literature Review}

There is a long list of empirical literature on consumption. For a recent treatment on the subject, see the overview in Muellbauer and Lattimore (1999), and the references therein, and Yoldas (2006) on the UK consumption function. Consumption is a feature of macroeconomic models since Keynes (1936) and is especially important for growth in transitional and EU accession countries, e.g. Bredin and Cuthbertson's (2001) paper on Czech Republic. Keynes is the first to postulate the relationship between consumption and disposable income. According to his views, consumers spend a fixed proportion of their current-period income. Those agents are regarded as "myopic" by Campbell and Mankiw (1990) because their consumption pattern is not consistent with inter-temporal optimization.

That is why the Life-Cycle Hypothesis ( $\mathrm{LCH}$ ) was developed by Modigliani and Brumberg (1954) and the Permanent Income Hypothesis (PIH) by Friedman (1957). LCH takes the individual lifespan as the planning horizon, while the PIH assumes a setup with infinitely-living agents (or "dynasties"). Both LCH and PIH allow for the 
income to vary across the planning horizon, and savings may be used to smooth consumption. That is consistent with reality because people are net debtors when young, net savers during their years of maturity, and net dis-savers during their retirement period. Thus LCH is influenced not only by income, but also by all assets held by the household.

PIH emphasizes the distinction between temporary vs. permanent changes in income. If the change in income is temporary, this will have only a small effect on the consumption behavior, as households would like to maintain a smooth consumption pattern. It is only when the change in income is permanent that consumers change their consumption by a sizeable amount. According to this theory, households look at their discounted future streams of income, which is known in the literature their permanent income. Thus Friedman claims that consumption is influenced by this aggregate rather than by the current income alone: changes in income will affect consumption with a lag.

Hall (1978) extended the LCH by adding rational expectations (RE). RE means that households behave as if they know the stochastic process that income follows. Consumers will not change their consumption plan unless new information makes them revise their expectations about the future income. According to Hall, if consumers' utility function is quadratic, both consumption and income follow a random walk (RW). If Hall's hypothesis is right, all lagged variables are in the households" information set as of the current period, so they should not be statistically significant. However, variables used by Hall are non-stationary and that leads to spurious regression - one that makes no statistical sense.

Flavin (1990) tests Hall's hypothesis in a structural framework. She finds that consumption reacts to predictable changes in income, something that goes against both $\mathrm{PIH}$ and LCH. That phenomenon is known in the literature as "excess sensitivity" of consumption. In another paper she finds that consumption is extraordinary smooth to unpredictable changes in income, again in conflict with PIH/LCH idea, which she calls "excess smoothness" of consumption.

Campbell and Mankiw's (1991) study encompasses both the Keynesian and PIH/ LCH hypotheses, much in the Hendry's (1993) "general-to-specific" methodology. In their model, some of the households are myopic, while the others follow PIH/LCH. The result they obtain violates the PIH - half of the US population bases its consumption pattern on current income. The reason behind that may be some liquidity constraints: a households acting according to PIH may be prevented to do so if it is unable to borrow when needed in order to smooth consumption. That may be proxied by the lending rate on consumption loans, for example.

Another approach to modeling consumption is the ECM approach of Davidson, Hendry, Srba and Yeo (DHSY) (1978). The authors present a dynamic time-series model of consumption, based on a long-run equilibrium relationship between consumption and income. They assume there is a long-run relationship between income 
and consumption. There is a steady-state and households are making short-run corrections to the equilibrium. If consumption exceeds long-run consumption, next period consumption will be decreased. Thus the EC term is expected to have a negative sign, and its coefficient to be less than one in absolute terms. This will show how much of the gap from the previous period will be closed in the next period.

After presenting the literature review, the paper proceeds to describe the data used in the study and discusses stationarity of the series. The section then presents the economic methodology that will be used to model the Bulgarian consumption function.

\section{Data description and Econometric Methodology}

For the empirical analysis, quarterly time series data from 1997:2 to 2005:4 will be used. The data will be obtained from the IMF International Financial Statistics (IFS) on-line database. All variables are measured in real terms, seasonally adjusted, and deated by the Consumer Price Index. Natural logs of the variables were taken to handle their magnitude and to express the coefficients of the variables as elasticities. Due to the very short series available for disposable income of households ( $g$ ndi) and gross national income (gni), we use gross domestic product $(g d p)$ series, which tracks the behavior of gni very closely, as seen from the Fig. 1 below.

Figure 1: Aggregate output and income in Bulgaria

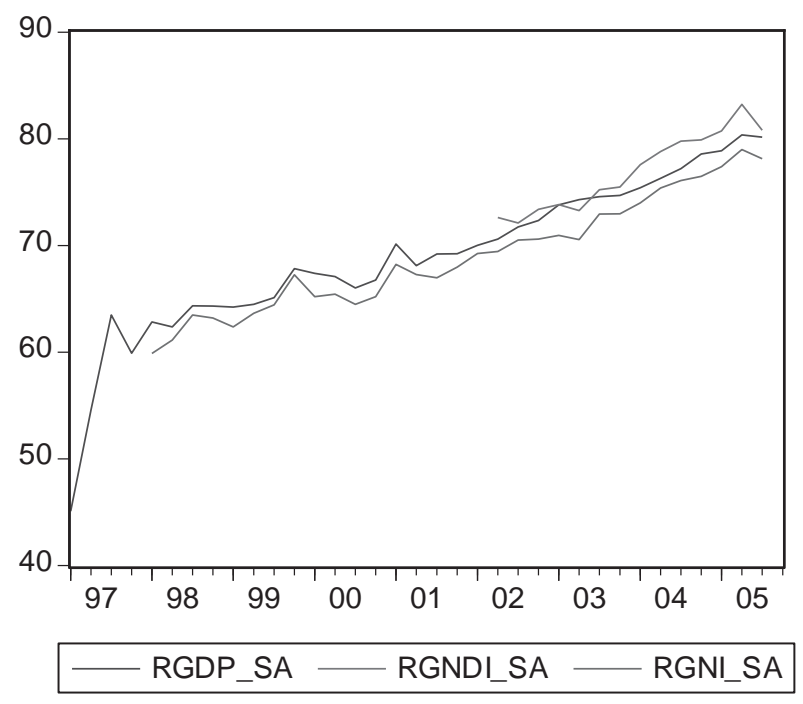


Before passing to estimation, we investigate the order of integration and trending behavior of all the variables using the Augmented Dickey-Fuller (ADF), as described in Dickey and Fuller (1984) and Said and Dickey (1984), and another popular alternative, the KPSS test, as in Kwiatkowski at al. (1992). ADF test was used with a constant but without a deterministic trend because usually economic time series have a stochastic trend. Phillips-Perron (1988) specification was not used because it uses a non-parametric correction for serial correlation, which in a sample of 34 observations has low power because its asymptotic properties are very weak. Our results are summarized in Table 1 below:

Table 1: Data description and stationarity

\begin{tabular}{|l|c|c|c|}
\hline Name of the variable & Notation & ADF & KPSS \\
\hline Ln of real household consumption(s.a) & Lrcons_sa & $\mathrm{I}(1)$ & $\mathrm{I}(1)$ \\
\hline Ln of Real Gross Domestic Product(s.a) & Lrgdp_sa & $\mathrm{I}(1)$ & $\mathrm{I}(1)$ \\
\hline
\end{tabular}

Since all the variables are intergrated of order 1, we transform them by taking differences, in order to make them stationary. Indeed, the first differences of the variables are integrated of order zero. After that we proceed with testing for the presence of co-integration between real consumption and income (in logarithms). The long-run relation between consumption and income was estimated, using the Engle-Granger (1987) two-step procedure. Johansen's (1991) Vector Error Correction estimation was not used because of the short time series available - it estimates too many parameters, too many unnecessary coefficients, which would result in imprecise estimates of the coefficients of the relevant variables.

The long-run relation between consumption and income was estimated using ordinary least squares (OLS). It turns out that there is evidence in favor of co-integration, and we are can reject the null hypothesis of the presence of a unit root in the residuals of the co-integrating relationship, using the co-integration ADF test as proposed by Engle and Yoo (1987). The results of the regression, with standard errors reported below the point estimates are as follows:

$$
\begin{gathered}
L R C O N S_{-} S A=0.12+0.89 * L R G D P_{-} S A \\
(0.27)(0.06) \\
R_{a d j}^{2}=0.86, S E E=0.03, N=34
\end{gathered}
$$

Next, we save the residuals from the equation and test for unit root (no co-integration) using ADF test. Note that since this is an estimated series, we have to use the critical value from Engle and Yoo (1987). For 2 variables in the co-integrating relationship and sample size of 34 observations, for 5\% level of significance the critical value of the ADF statistic is -3.29 . We safely reject the hypothesis of the presence of a 
unit root in the residuals and conclude that there is a stable co-integrating relationship, and we will refer the variable in what is to follow as the "Error-Correction-Term." For robustness check we also use the co-integration Durbin-Watson (DW) test statistic, as suggested by Engle and Granger (1987). Since the DW test statistic exceeds the critical value $(1.36>0.78)$, we can again reject the presence of a unit root and show there is a long-run relationship between consumption and income. This relationship can be also seen with a naked eye in Fig. 2 below:

Figure 2: Behavior of consumption and output in Bulgaria

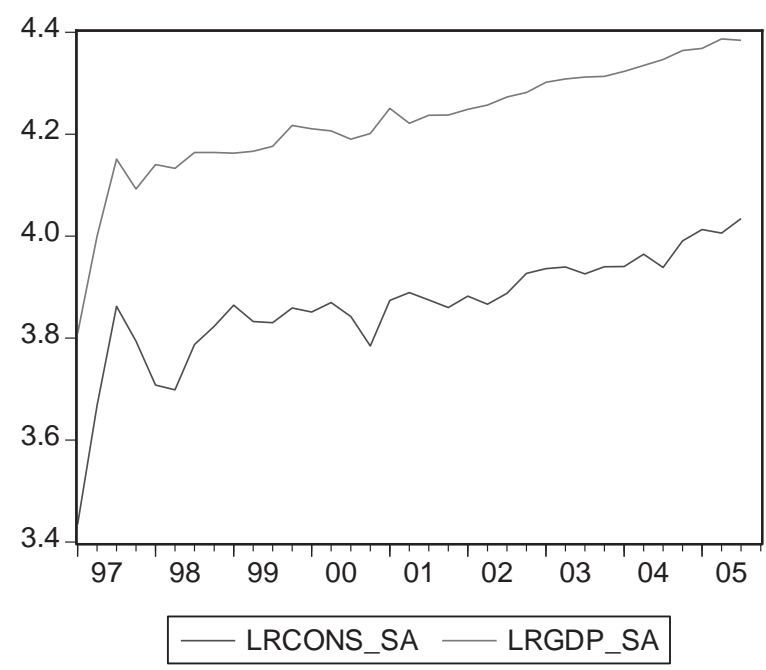

Source: IFS (2005)

Next, we investigate the short-run dynamics of consumption using an all encompassing regression in first differences: thus, diffrcons_sa and diflrgdp_sa are the first difference of the seasonally adjusted and logged series of aggregate real consumption and output. Because the total number of observations is only 34, we limit our starting lag length to 4. Proceeding in line with Hendry's (1993) "from general to simple" econometric principle, we drop the redundant lags from the regression, controlling for their joint significance. The final model is presented on the next page, where "Lx." in front of a variable denotes the " $x$ "-th lag of the respective variable, and ECT is the error-correction term estimated from the earlier equation:

DIFLRCONS_SA $=0.0065-0.773 *$ L1.DIFLRCONS_SA $-0.727 *$ L2.DIFLRCONS_SA

$-0.23 *$ L3.DIFLRCONS_SA $+0.957 *$ DIFLRGDP_SA $+0.572 *$ L1.DIFLRGDP_SA+

$+0.16 *$ L4.DIFLRGDP_SA $1.197 * L 1 . E C T-0.629 * L 4 . E C T$ 
All explanatory variables, aside from the constant, are individually statistically significant at $1 \%$. The constant is individually marginally significant at $5 \%$. All variables are jointly significant at $1 \%$, as indicated by the F-statistic (F-stat=52.42), and adjusted R-square (0.93). The additional tests performed for autocorrelation in residuals, their normality, functional form of the model and stability of coefficients suggest the validity of the above model. It is apparent that Bulgarian consumers demonstrated a purely Keynesian attitude after the crisis: after the introduction of the currency board in 1997 they were adjusting their consumption to changes in current income within 2 periods. The last proposition merits further investigation within the framework of Campbell and Mankiw's (1991) model, which requires running a simple OLS of diflrcons_sa on diflrgdp_sa, and obtained the following results (again, standard errors are reported below the point estimates):

$$
\begin{aligned}
\text { DIFLRCONS_SA }=-0.002+1.13 * \text { DIFLRGDP_SA } \\
(0.007)(0.15) \\
R_{a d j}^{2}=0.63, S E E=0.034, N=34
\end{aligned}
$$

A potential problem that might arise from the regression above is that there may be some endogenous relationship between the two variables, in which case OLS will give biased and inconsistent estimates. Thus we conduct the Hausman test of the Mankiw-Campbell equation to determine whether OLS introduces a bias in the estimates of coefficients. We choose the 4 lags of diftrcons_sa as instruments, and regress income on them to get the residuals, which will be then used for the Hausman test diagnostics. More specifically, the residuals are going to be included in the Mankiw-Campbell equation as an additional control, and we will check for their individual significance. As seen from the results on the next page, it turns out that the OLS produces consistent estimates of the income elasticity of consumption, since the coefficient in front of the residual term (RESID) is not statistically different from zero, while the other point estimates and their standard errors (not reported) do not change significantly.

DIFLRCONS_SA $=-0.002+1.18 * D I F L R G D P \_S A+0.48 * R E S I D$

$$
R_{a d j}^{2}=0.65, S E E=0.039, N=29
$$

In addition, since the coefficient in front of diflrgdp_sa is not statistically different from 1, Campbell-Mankiw's (1991) model suggests that we cannot reject the hypothesis that all Bulgarian consumers behave in a myopic way. The ratio $\mathrm{C} / \mathrm{Y}$ is stationary and is stabilizing at 0.7, meaning that households in Bulgaria spend $70 \%$ 
of their current income. Such a behavior is very different from the models based on inter-temporal optimization used to model households' behavior in Western economies.

\section{Conclusion}

In this paper, an econometric model of consumption in Bulgaria for the period 19972005 was constructed. The Error-Correction Model (ECM) approach was employed and long-run relationship between household consumption and income was found. The primary purpose of this empirical paper was to get a better understanding of the factors driving household consumption in Bulgaria and to estimate a consumption function to be used for medium-term forecasting. It was shown that all households behave in a Keynesian way, basing their consumption decisions on current income. It is worth emphasizing that private consumption expenditure is the largest component of the Gross Domestic product (GDP) in Bulgaria and an extremely important component of the aggregate demand. That is not only because it influences economic growth, but also for business cycle considerations. In this respect, the study of consumption is relevant, because it suggests that macroeconomists working on theoretical models on Bulgarian economy within the dynamic stochastic general equilibrium framework maybe should model households' behavior in the Keynesian tradition as hand-to-mouth and myopic, instead of being represented as agents that smooth their consumption over time, as the former is a better approximation of reality.

\section{REFERENCES}

Bredin, D. and K. Cuthbertson (2001). "Liquidity Effects and Precautionary Saving in the Czech Republic," Central Bank of Ireland Technical Paper 4/RT/01.

Campbell, J., N. Gregory Mankiw (1991). "The response of consumption to income: A cross-country investigation," European Economic Review 35 (4): 723-756

Chukalev, G. (2010) "Consumption, Income and Household Wealth," Agency for Economic Analysis and Forecasting Working Paper 2, Sofia, Bulgaria.

Davidson, J.E.H., D.F. Hendry., F. Srba. and S. Yeo (1978). "Econometric Modelling of Aggregate Time Series Relationship between Consumers, Expenditure and Income in United Kingdom," The Economic Journal, 88, pp. 661-692.

Dickey, D.A. and Fuller, W.A. (1981). "Distribution of the estimators for autoregressive time series with a unit root." Econometrica 49, 1057-72.

Engel, R.F. and C.W.J. Granger (1987). "Co-intergration and Error Correction: Representation, Estimation and Testing," Econometrica, 55(2), pp. 1039 - 1089.

Flavin, M. (1981). "The Adjustment of Consumption to Changing Expectations about future income," Journal of Political Economy, 89 (5) pp. 974-1009. 
Friedman, M. (1957). A Theory of the Consumption Function, Princeton University Press, Princeton.

Genchev, E. (2012) "Analysis of income-consumption relationship in Bulgaria and Russia," Young Scientist 4: 115-9.

Hall, R.E. (1978). "Stochastic Implications of the Life Cycle Hypothesis: Theory and Evidence," Journal of Political Economy 86, pp. 971-987.

Hendry, D. F. (1993) Econometrics: Alchemy or Science? Essays in Econometric Methodology. Blackwell Publishers: Oxford, UK.

International Monetary Fund (2005). International Financial Statistics Database. Available on-line at: www.imf.org.

Johansen, S. (1991). "Estimation and Hypothesis Testing of Cointegration Vectors in Gaussian Vector Autoregressive Models." Econometrica 59 (6): 15511580.

Keynes, J.M. (1963). The General Theory of Employment, Interest and Money. Oxford Bulletin of Economics and Statistics 54 (3), pp. 325-348.

Kwiatkowski, D., Phillips, P. C. B., Schmidt, P., Shin, Y. (1992). "Testing the null hypothesis of stationarity against the alternative of a unit root". Journal of Econometrics 54 (13): 159-178.

Lucas, Rober E., Jr (1976) "Econometric Policy Evaluation: A Critique. Studies in Business-Cycle Theory”. The MIT Press: Cambridge, MA.

Modigliani, F. and R. Brumberg (1954). "Utility Analysis and the Consumption Function: An Interpretation of Cross-Section Data," In Post-Keynesian Economics, ed. K. Kurhira. New Brunswick, NJ: Rutger University Press.

Muellbauer, J. and R. Lattimore (1999). "The Consumption Function: A Theoretical and Empirical Overview," in: Handbook of Applied Econometrics. Volume I: Macroeconomics, M. Hashem Pesaran and Michael R. Wickens (eds.), Blackwell Publishing.

Petrova, P., G. Stoianova, I. Gueorguiev. (1996) "Application of the Cointegration Analysis: Ination. Consumer Function,” Agency for Economic Analysis and Forecasting, Sofia,Bulgaria.

Phillips, P., and Perron, P. (1988). “Testing for a Unit Root in Time Series Regression”.Biometrika 75 (2): 335346.

Said, S., and Dickey, D. (1984). “Testing for Unit Roots in Autoregressive-Moving Average Models of Unknown Order". Biometrika 71 (3): 599-607.

Skoufias, Emmanuel (2004). Consumption Smoothing During the Economic Transition in Bulgaria. Journal of Comparative Economics 32 (2) (2004) 328-347.

Yoldas, I. (2006) "Modelling Aggregate UK Consumption Function: A Time Series Analysis," B.Sc. Dissertation, University of Southampton, Mimeo. 